\title{
Potestad Sancionadora de la Administración Tributaria ${ }^{23}$
}

\author{
Gabriel Martín Alvarado Brenes \\ Labora en el Poder Judicial \\ gabrenes52@hotmail.com
}

\begin{abstract}
Resumen
A lo largo de la investigación que se enuncia la atribución conferida al Estado en el ejercicio tributario, refiriéndonos al poder punitivo que ostenta éste frente a las violaciones que realicen los sujetos pasivos a la legislación tributaria.
\end{abstract}

En esta misma línea, pretendo exponer algunas deficiencias jurídicas que presenta la normativa fiscal, al delegar facultades de carácter legislativo a la Administración Tributaria, para complementar deficiencias jurídicas existentes en la norma tributaria con el fin de lograr el cumplimiento por parte de los contribuyentes de las obligaciones tributarias.

Palabras clave: Ejercicio tributario/ modelo social de derecho/ Principios de potestad sancionadora/ infracciones administrativas/delegación legislativa

\begin{abstract}
During the investigation it appears, it sets the power conferred upon the State in the tax year, referring to the punitive power which holds it against violations that taxpayers make tax law.

In the same vein, I intend to present some legal deficiencies presented by the tax legislation by delegating legislative powers to the tax authorities to complement existing legal deficiencies in the tax rule in order to achieve compliance by taxpayers in tax obligations.
\end{abstract}

Key words: Tax year/ social model of law/ Principles of sanctioning authority/ administrative offenses/ legislative delegation

23 El presente artículo es el resultado del trabajo de investigación realizado para obtener el título de Especialista en Derecho Económico; el cual además de ser evaluado por un Tribunal integrado por tres académicos; posteriormente, fue arbitrado por una Comisión a efectos de seleccionar a los participantes del II Encuentro de Investigación de Postgrado de la Universidad Centroamericana, Agosto 2010. 


\section{Introducción}

La presente investigación es un trabajo documental desarrollado en cinco (05) capítulos: el primero, hace referencia a la atribución conferida al Estado para legislar en materia tributaria, conocido por la doctrina como ejercicio del poder tributario; precisando su avance a través del tiempo para luego pasar a analizar notas caracterizadores y distinciones sobre el mismo.

Por otro lado, se señalan los principios de justicia tributaria, enfocándonos en los de índole formal, por ser éstos los que limitan la actuación y comportamiento de los sujetos que ostentan la facultad de crear los tributos y de aplicar las normas tributarias.

Seguidamente, expongo las fuentes inspiradoras por el Código Tributario en esta materia, partiendo de la definición de fuentes como aquello que da nacimiento $u$ origen a las normas jurídicas, donde a la vez introduzco breves notas definitorias para cada una de ellas.

Posteriormente, presento elementos teóricos, doctrinales y jurídicos sobre el ejercicio del poder punitivo del Estado en esta esfera jurídica, refiriéndome específicamente al ilícito tributario de índole administrativo: las infracciones tributarias; los elementos que la componen y los principios inspiradores del ejercicio sancionatorio por parte de la administración tributaria, hasta concluir con los considerados sujetos infractores a las normas tributarias.

\section{El poder tributario}

\section{Evolución histórica}

Me parece indispensable empezar el desarrollo de esta investigación, presentando el estudio realizado sobre este acápite por Queralt (2001) exponiendo que, tradicionalmente, se ha considerado que el poder para establecer tributos, junto con el poder para acuñar moneda y para declarar la guerra, constituye el núcleo identificador de la soberanía política:

La competencia para establecer tributos ha sido siempre uno de los distintivos tradicionales de la soberanía política, al punto 
de que cuando las primeras instituciones parlamentarias - las asambleas medievales - se reúnen, para discutir asuntos públicos, lo hacen con la finalidad muy concreta: estudiar y, en su caso, aprobar, las peticiones de subsidios hechas por los monarcas, condicionando su concesión al hecho de que se diera explicación sobre las actividades que iban a financiarse con los medios solicitados (p. 143).

Aquí se dio inicio a un hecho histórico importante: el sistema del parlamentarismo surge íntimamente asociado a las instituciones financieras, a la necesidad de aprobar unos ingresos y gastos públicos.

Posteriormente, con el surgimiento del constitucionalismo en el siglo XIX, tanto la imposición de tributos como la aprobación de los presupuestos estatales se trasladaron a ser competencia reservada al Parlamento, y por consiguiente, tanto la aplicación y efectividad del tributo como la ejecución del presupuesto, constituye una actividad administrativa reglada, adscrita a Derecho.

De este modo, se llegó al desenlace de un largo proceso histórico, el que surgió con el establecimiento de tributos a los pueblos vencidos en contiendas bélicas, y que finalizó con la imposición de tributos por el parlamento de manera ordenada y, como hemos señalado, conforme a Derecho. El tributo ya no figuraría como símbolo de poderío militar, sino como instituto jurídico que adquiere carta de ciudadanía en el mundo del Derecho. En este marco, el poder tributario deja de ser un arsenal de potestades discrecionales e ilimitadas para convertirse en el ejercicio de competencias por parte de un órgano - el Parlamento - al cual la Constitución limita (Martín Queralt, 2001).

\section{Nociones generales}

Expuesto el origen histórico del poder tributario, es menester referirnos a la competencia para el establecimiento de tributos, y a la definición de potestad aportada por García de Enterría quien señala:

La potestad no corresponde ningún deber, sino una simple sujeción o sometimiento. El deber podrá surgir eventualmente de la relación jurídica que el ejercicio de la potestad es capaz de crear, pero no del simple sometimiento a la potestad misma. No hay 
por ello, ante la potestad, un sujeto obligado, sino una situación pasiva de inercia, que implica un sometimiento a los efectos que la potestad puede crear en su ejercicio, la inexcusabilidad de soportar que tales efectos se produzcan y que por casualidad afecten a la esfera jurídica del sometido (Martín Queralt, 2001, p. 152).

En esta línea es menester señalar que la capacidad del Estado para crear, aprobar, modificar, suprimir y aplicar el sistema de tributos, es lo que se conoce como Poder Tributario. Esto se encuentra recogido en el texto de los artículos ciento catorce y ciento treinta y ocho numeral veintisiete de la Constitución Política de Nicaragua, los que íntegramente dicen:

Art. 114 Cn: Corresponde exclusivamente y de forma indelegable a la Asamblea Nacional la potestad de crear, aprobar, modificar o suprimir tributos. El sistema tributario debe tomar en consideración la distribución de la riqueza y de las rentas. Se prohíben los tributos o impuestos de carácter confiscatorio... Art. 138.27 Cn: Son atribuciones de la Asamblea Nacional: Crear, aprobar, modificar o suprimir tributos y aprobar los planes de arbitrios municipales.

Este poder que ejerce el Estado, según la proyección de sus propios poderes; se utiliza con el fin de obtener ingresos de manos de los particulares, para ayudar a financiar el gasto público en aras de la consecución del bien común. En consecuencia, implica esa facultad o posibilidad jurídica del Estado de exigir contribuciones con respecto a personas o bienes que se hallan en su jurisdicción. (Bermúdez Pérez, 2009).

Sobre esta línea, de acuerdo con González García (2000):

En la doctrina mayoritaria suele hablarse de potestad tributaria en dos sentidos distintos que contemplan respectivamente, la acción del Estado como legislador y como administrador. En primer sentido, se habla de poder o potestad tributaria refiriéndose al Poder Legislativo que corresponde al Estado, expresión, en último término de su soberanía. En el segundo, se está aludiendo al poder o potestad de la Administración Pública tendiente a aplicar las normas tributarias (p. 119). 
Así pues, son dos acepciones distintas de una misma locución, que requieren ser diferenciadas, a la luz de las aportaciones de Micheli en potestad tributaria normativa a la primera y potestad de imposición a la segunda, "terminología que es acorde con la duplicidad de planos en la consideración de la actuación del Estado, es decir, abstracto y concreto, o bien legislativo y ejecutivo, correspondientemente" (González García, 2000, p. 120).

En adición a esto, Balladares Saballos (2007) expresa que:

La potestad tributaria normativa consiste en el poder para dictar normas jurídico-tributarias por parte del Estado, esto es, crear tributos a través de leyes, mientras que la potestad de imposición es el conjunto de atribuciones que suponen la aplicación del sistema tributario delineado legalmente a efectos de la liquidación, recaudación y gestión de los tributos. En el primero de los casos el Estado actúa en un plano abstracto o fase normativa, mientras que en el segundo, opera en un plano concreto o fase aplicativa (p. 240).

Nuestra norma suprema es clara al señalar en los artículos ciento catorce y ciento treinta y ocho numeral veintisiete, la potestad tributaria normativa conferida de forma indelegable y con exclusiva jurisdicción a la Asamblea Nacional para crear, aprobar, modificar y suprimir tributos. En materia de aplicación de los mismos, la potestad de imposición se delega al Poder Ejecutivo, el cual por medio de la Dirección General de Ingresos o la Dirección General de Servicios Aduaneros (entre otros entes públicos), es el encargado de la recaudación de los mismos. Sin embargo, conviene señalar en relación con los tributos municipales a cargo de los gobiernos locales o municipales que las Alcaldías son las responsables de la recaudación de los mismos.

De acuerdo con Balladares Saballos (2007), "la potestad tributaria normativa constituye un aspecto más del Poder Legislativo del Estado, expresión de la soberanía que corresponde de forma exclusiva e indelegable al pueblo, ejercida por los representantes legítimamente electos” (p. 241), así lo contempla el art. 2 Cn., al expresar que:

La soberanía nacional reside en el pueblo y la ejerce a través de instrumentos democráticos, decidiendoy participando libremente en la construcción y perfeccionamiento del sistema económico, 
político y social de la nación. El poder político lo ejerce el pueblo, por medio de sus representantes libremente elegidos por sufragio universal, igual, directo, libre y secreto, sin que ninguna otra persona o reunión de personas pueda arrogarse este poder o representación. También podrá ejercerlo de manera directa por medio de referéndum y del plebiscito y otros procedimientos que establezcan la presente Constitución y las leyes.

No obstante, existen diversos niveles de gobiernos que poseen autonomía en materia tributaria, lo cual conlleva un problema estructural en el Derecho Tributario nicaragüense, identificándose para efectos de resolver dicho problema, dos conceptos: potestad tributaria normativa originaria y potestad tributaria normativa derivada.

En este sentido, conviene recalcar la base sobre la que se asienta esta distinción, esto es, la fuente jurídica de la que una y otra proceden; y en este caso, encontramos que la potestad tributaria normativa originaria posee su fuente en la Constitución, mientras que la ley ordinaria para el caso de la potestad tributaria normativa derivada. (González García, 2000).

Merece detenernos y entrar a desarrollar lo referido al grado de ejercicio de la potestad tributaria normativa derivada. En el caso de Nicaragua, se ha expuesto anteriormente que el art. $114 \mathrm{Cn}$. enuncia de forma clara que a la Asamblea Nacional le corresponde de forma exclusiva e indelegable la potestad de crear, aprobar, modificar o suprimir tributos; sin embargo, la problemática está en los límites y contenido del ejercicio de la posible potestad tributaria normativa de rango reglamentario por parte de los gobiernos municipales y el Poder Ejecutivo, mismo que deben ser afín con la norma constitucional y fundamentalmente con la ley sobre la cual se pretenden establecer normas de desarrollo con rango de reglamento.

De todo lo anteriormente relacionado, podemos concluir que la distinción entre potestad tributaria normativa originaria y potestad tributaria normativa derivada, no implica un problema en nuestro caso, puesto que la Constitución Política es clara al determinar la reserva exclusiva de tal potestad al Poder Legislativo. (Balladares Saballos, 2007). 


\section{Los principios de justicia tributaria}

De acuerdo con Calvo Ortega (1997) citado por Bermúdez Pérez (2009, p. 9) expresa lo siguiente:

Para que las normas del Derecho Tributario logren el fin buscado, en un principio, deben introducirse en su producción, la intención por parte de los poderes públicos de la realización de los principios de justicia tributaria. En este sentido, las normas tributarias están sometidas a los principios de generalidad y capacidad económica.

Así pues, se diferencian los principios de las normas, por su aspecto temporal frente a las segundas, pues aquellos no son sujetos de derogación. Tienen un rol predominante al estar envestidos de una mayor capacidad de acción, por cuanto su función metodológica ayuda en la producción y aplicación de las normas, a pesar de que su aplicabilidad no es directa. (Calvo Ortega, 1997).

Al señalar que se trata de "principios" se está precisando su carácter básico como soportes primarios, estructurales del sistema entero del ordenamiento, al que por ello prestan todo su sentido. Los principios expresan valores materiales básicos e informadores de un ordenamiento jurídico, sobre las cuales se constituyen como tal, si bien las convicciones ético jurídicas fundamentales de una comunidad. (Bermúdez Pérez, 2009).

El hecho de que las normas tributarias incluyan un trato previo en los planteamientos de los principios, presupone un interés en la defensa de los ciudadanos, ante cualquier arbitrariedad cometida por los poderes públicos. De este modo, ante la oscuridad que puedan presentar las normas tributarias, los principios proveerán respuestas a los contribuyentes ante tales omisiones, ayudando a que los tributos se apliquen acorde con los principios que, inicialmente, han inspirado su creación.

Dicho esto, el Considerando III de nuestro Código Tributario nos plantea el acogimiento de este método principialista, razonando su creación ante las debilidades que poseían las leyes tributarias anteriores, en tanto que recoge los principios esenciales y regula, de forma coherente, las relaciones entre la Administración Tributaria y los contribuyentes. 
De lo anteriormente expuesto, es menester hacer referencia que los principios son los límites fundamentales al ejercicio de la atribución constitucional otorgada al Estado para efectos de crear, modificar, suprimir y aplicar el sistema de tributos, mismos que son utilizados con el fin de garantizar la defensa y garantías de los contribuyentes. (Balladares Saballos, 2007).

En este sentido, considero necesario que este conjunto de criterios, que dirigen e inspiran al legislador y juzgador cuando el caso lo requieran, suple las insuficiencias o ausencias de la ley y otras fuentes formales, a la vez que deberían estar positivados, es decir, recogidos en la propia norma tributaria a los efectos de evitar su deducción del propio sistema de normas, donde éstos se puedan localizar de forma tácita o expresa.

Dicho todo esto, los principios de justicia tributaria encuentran su fuente, como no podría ser de otra forma, en la Constitución Política de Nicaragua, unos en forma específica y de forma más directa y otros de forma no tan claramente definida en nuestro texto constitucional, por lo que se requiere realizar una labor interpretativa para poder vincularlos.

En adición a esto, Jaentschke Acevedo (2008, p. 9) haciendo referencia a Ferreiro Lapatza (1990), dice que:

La Constitución de Nicaragua, refleja la idea de justicia, que una comunidad organizada políticamente profesa en un momento histórico determinado, y los principios constitucionales de justicia tributaria reflejan por tanto, la idea de lo justo, referida a la concreta esfera de los tributos. Por ello, las normas tributarias han de ser entendidas siempre como parte de la Constitución, limitadas, enmarcadas por el resto de las normas que forman parte de ella. El legislador a la hora de implementar y crear tributos debe tener en cuenta toda la Constitución, aunque normalmente se inspire en las normas constitucionales que específicamente se refieren a la materia del tributo.

En la legislación tributaria, el motivo de los principios, propone clasificarlos en principios de justicia tributaria material y principios de justicia tributaria formal, atendiendo a su denominación los primeros inciden en la delineación del contenido y cualidades de la prestación jurídica tributaria (contenido), mientras que los últimos determinan cómo debe hacerse o crearse la prestación (continente del tributo). 


\section{Principios formales de justicia tributaria}

Considerados como los que velan por las solemnidades que deben observar los legisladores para la producción, reforma o derogación de tributos, en el caso que nos ocupa, nos remiten a los principios de legalidad, seguridad jurídica y reserva de ley.

\subsection{Principio de legalidad}

Enunciado en el artículo tres del Código Tributario, y complementado con los artículos ciento quince y ciento treinta y ocho de la Constitución Política, es considerado como principio clave de fuente de derecho. Este principio señala que es necesaria una ley formal para el establecimiento de tributos, entre los cuales se incluyen los tributos y los sujetos pasivos de la obligación tributaria. De este modo, se reserva a la ley un lugar privilegiado en el ordenamiento jurídico (Pérez Royo, 2001).

Según González García (2000) el principio de legalidad implica que solo mediante ley pueden ser impuestos por el Estado sacrificios patrimoniales a los ciudadanos. El precepto inspira, por una parte, el principio de auto imposición, mejor conocido en el constitucionalismo moderno como no taxation without representation, o en el mundo romano, como "lo que a todos afecta, por todos debe ser aprobado".

De igual modo, este principio de legalidad inspira la apertura de mecanismos revisores en vía constitucional o administrativa, esto es, los recursos que le asisten al contribuyente en una u otra vía.

\subsection{Principio de reserva de ley}

En adición al criterio del principio de legalidad en materia tributaria, la reserva de ley implica que solo la función legislativa, de manera absoluta tiene la reserva exclusiva de crear, aprobar, modificar o derogar el sistema tributario de conformidad con el artículo ciento quince de la Constitución Política.

De acuerdo con Pérez Royo (2001), refiriéndonos a la función esencial de lo que la reserva de ley debe cubrir, bien podemos señalar que ésta se refiere a todos aquellos elementos que afectan a la identidad o la entidad de la prestación, como son la determinación de los sujetos pasivos, el 
presupuesto de hecho, la base imponible, el tipo de gravamen, la cuota, en fin, todos los elementos cuantitativos del tributo.

Así pues, la reserva de ley exige que sea por medio de ley que se le imponga al contribuyente una afectación en su patrimonio a manera de tributo.

\subsection{Principio de seguridad jurídica}

La certeza y objetividad de la norma tributaria, así como la prohibición o la interdicción de la arbitrariedad en materia tributaria, son las características que constituyen el principio de seguridad jurídica. (Balladares Saballos, 2007).

En su aspecto positivo, este principio, determina que la ley constituye certeza jurídica, en su aspecto negativo a raíz de la formación de la norma; ésta se utiliza a manera de defensa a las posibles arbitrariedades de los órganos del Estado. (Cortés Domínguez, 1977).

Este mismo precepto, lo acoge nuestro Código Tributario en su Considerando V, al enunciar:

Quepor seguridadjurídica debeentendersela posibilidad deprever las consecuencias y el tratamiento tributario de las situaciones y actuaciones de los contribuyentes, pudiendo pronosticar, de previo, las correspondientes decisiones administrativas y judiciales sobre tales situaciones y acciones. Sobra decir que en la medida en que se observa dicho principio se promueve la plena confianza de los ciudadanos en sus instituciones y se le proteja de la arbitrariedad.

De esta manera, me limito a enunciar estos principios encaminados a la parte formal, al considerar que los mismos limitan el ejercicio del poder público, evitando de esta manera la arbitrariedad sancionatoria y dotando de justicia al sistema tributario.

\section{Fuentes del Derecho Tributario}

Habiéndose expuesto los titulares de la potestad de establecer tributos o de dictar normas en esta área de estudio; habrá que hacer referencia a los modos de creación de estas normas, esto es a las fuentes del derecho en el área tributaria. 
De acuerdo con Flores Valeriano (1990), la teoría que estudia el origen, elaboración y manifestación, en la sociedad, de las normas que integran el sistema jurídico-positivo de un país confronta el problema de definir y clasificar las fuentes del Derecho, ya que ésta tiene acepciones diferentes:

Fuente del Derecho, puede significar: a) fuente del conocimiento de lo que históricamente es o ha sido Derecho, (antiguos documentos, colecciones legislativas, etc.; b) fuerza creadora del Derecho como hecho de la vida social (la naturaleza humana, el sentimiento jurídico, la economía, etc.); c) autoridad creadora del Derecho histórico o actualmente vigente (Estado, pueblo, etc.); d) acto concreto creador del Derecho (legislación, costumbre, decisión judicial, etc.); e) fundamento de la validez jurídica de una norma concreta de Derecho, f) forma de manifestarse la norma jurídica (Ley, decreto, reglamento, costumbre, etc.); g) fundamento de un derecho subjetivo. (p. 147).

En la zona del Derecho Tributario, al igual que sucede en el conjunto de ordenamiento jurídico público, la teoría de las fuentes del Derecho se circunscribe prácticamente a los modos de creación del Derecho escrito, de la ley en sentido material.

Es fuente del Derecho, entonces, todo aquello que da nacimiento al Derecho objetivo, es decir, aquello que da nacimiento o de donde se originan las normas jurídicas. (Escorcia, 2002).

En adición a esto, podemos resaltar lo que expresa González García (2000):

Los principios fundamentales de la teoría general de las fuentes del Derecho con especial referencia al Derecho Público, son directamente trasladadas al campo del Derecho Tributario; segunda, las peculiaridades que en este terreno pueda presentar el Derecho Tributario, son directa consecuencia de la relevancia especialísima que dentro de su ámbito juega el principio de legalidad, tanto en su esfera normativa (principio de reserva de ley) como en la aplicativa (principio de legalidad de la Administración). (p. 51).

Dicho esto, podemos concluir que las fuentes reconocidas por nuestro ordenamiento jurídico son aplicables al Derecho Tributario, y que en 
ésta esfera normativa rige el sistema de jerarquía establecido en primer lugar por la Constitución, y en segundo término por nuestro Código Tributario (Balladares Saballos, 2007).

Así pues, en el ámbito tributario nicaragüense, el art. 2 CTr., enuncia las fuentes en ésta orbita jurídica, y en este sentido reza:

Art. 2. Son fuentes del Derecho Tributario:

1. La Constitución Política de Nicaragua;

2. Las leyes, inclusive el presente Código Tributario;

3. Los tratados, convenios o acuerdos internacionales vigentes;

4. Los reglamentos y disposiciones que dicte el Poder Ejecutivo en el ámbito de su competencia;

5. La jurisprudencia de la Corte Suprema de Justicia; y

6. Las disposiciones de carácter general que emita el titular de la Administración Tributaria con fundamento en las leyes respectivas y en estricto marco de su competencia.

Siendo que en éste ámbito rige el principio de jerarquía de la norma, Escorcia (2002) refiere a éste y dice:

Lo que implica el sistema de jerarquía, es que una fuente o norma prevalece sobre otra, en función del rango de la autoridad o del órgano de que se emanen. La ordenación vertical de las fuentes, según el principio de jerarquía, supone una estricta subordinación entre ellas, de forma tal, que la norma superior siempre deroga la norma inferior (y a esto se le conoce como fuerza activa de la norma) y la inferior es nula cuando contradiga la norma superior (y esto es la fuerza pasiva) (p. 138).

Dicho todo esto, la disposición legal antes referida, nos señala la estructura de las fuentes normativas del Derecho Tributario nicaragüense, por lo que es meritorio introducir cada una de ellas.

\section{La Constitución Política de Nicaragua}

La primera de las fuentes de la normativa tributaria es la Constitución, norma prevaleciente que se impone y condiciona a todas las demás, ya sean de origen legislativo como gubernamental. 
En cuanto a los preceptos constitucionales que afectan específicamente a los tributos, encontramos los artículos ciento catorce, ciento quince y ciento treinta y ocho en su inciso veintisiete que nos refieren a los principios constitucionales sobre tributos; mismos que señalan la potestad tributaria normativa y una reserva de ley absoluta en normativa tributaria.

\section{Las leyes - el Código Tributario}

El Derecho interno de rango ordinario o infraconstitucional señala que la primera de las fuentes es la Ley, la cual tiene un papel central en el Derecho Tributario por imperativo del principio de legalidad (art. $115 \mathrm{Cn}$ ), que exige un rango formal para la regulación de los elementos esenciales del tributo.

Así pues, la creación, modificación o anulación de un tributo, puede ser únicamente verificada a través de una ley; y en este mismo sentido el art. 3 del C.Tr reza:

Art. 3. Solo mediante ley se podrá:

1. Crear, aprobar, modificar o derogar tributos;

2. Otorgar, modificar, ampliar o eliminar exenciones, exoneraciones, condonaciones y demás beneficios tributarios;

3. Definir el hecho generador de la obligación tributaria; establecer el sujeto pasivo del tributo como contribuyente o responsable; la responsabilidad solidaria; así como fijar la base imponible y de la alícuota aplicable;

4. Establecer y modificar las preferencias y garantías para las obligaciones tributarias y derechos del contribuyente; y

5. Definir las infracciones, los delitos y las respectivas sanciones.

La ley es el mandato jurídico, aprobado por el Poder Legislativo, no susceptible de otro control que el de constitucionalidad. Dentro de la ley podemos distinguir, en primer lugar, entre las leyes Orgánicas y las Ordinarias. A como expone Pérez Royo "la doctrina mayoritaria considera que la diferencia entre unas y otras no es de rango sino de ámbito de regulación" (2001, p. 59). En este sentido, en nuestro ordenamiento jurídico, el legislador ha venido creando y dándole nombre muchas veces sin percatarse cuál es la naturaleza intrínseca de tales normas. 
Hablamos pues, de leyes ordinarias definidas en forma negativa como aquella que no es de rango constitucional, y en la que rige el principio de competencia, y de leyes orgánicas denominadas así a aquellas leyes que se refieren a la estructura del poder público, o las referidas a un ente estatal específico (Escorcia, 2002).

Es objeto hacer especial mención entre las normativas tributarias, el Código Tributario, aprobado el veintiocho de Octubre del año dos mil cinco y publicado en La Gaceta, Diario Oficial No 227 del veintitrés de Noviembre del año dos mil cinco; mismo que entró en vigencia en virtud de vacatio legis el Veintitrés de Mayo del año dos mil seis; y reformado por la Ley $\mathrm{N}^{0} 598$, Ley de Reforma a la Ley $\mathrm{N}^{0} 562$, Código Tributario de la República de Nicaragua; La Gaceta, Diario Oficial No 117 del 11 de Septiembre de 2006; es ésta la única que interesa directamente a la materia tributaria ya que regula el ejercicio de la competencia tributaria.

\section{Los tratados, convenios o acuerdos internacionales vigentes}

Los acuerdos internacionales firmados por el Poder Ejecutivo con otros países soberanos en el plano internacional, conforme la Constitución Política, aprobados por el Poder Legislativo, publicados en "La Gaceta", Diario Oficial son instrumentos legales obligatorios de aplicación nacional y, por consiguiente, fuente del Derecho en materia tributaria nicaragüense, según el caso.

El inciso doce del artículo ciento treinta y ocho de la Constitución Política de Nicaragua, faculta a la Asamblea Nacional para aprobar o rechazar los instrumentos internacionales; sin embargo, esa limitada atribución no la faculta para modificar cláusulas o modificar el tratado; por lo que una vez aprobado éste se integra al ordenamiento jurídico como cualquier ley, lo que conlleva al inconveniente de que si se aprobase un tratado que contravenga disposiciones de carácter constitucional, esto tendría que solucionarse impugnando por Inconstitucionalidad el tratado como cualquier ley, al tenor del artículo ciento ochenta y dos de la Constitución Política. Es conveniente señalar en este apartado si una ley podría, de forma tácita, modificar materias de un tratado internacional y, en caso de conflicto, cuál norma es la prevaleciente. En este sentido, nos encontraríamos ante una antinomia de normas misma que sería objeto de discusión ante el órgano competente para este caso. 


\section{Los reglamentos y decretos}

Dentro de las fuentes del Derecho Tributario el reglamento, al igual que en las otras disciplinas jurídicas, desempeña un papel que propicia la aplicación y ejecución de los preceptos legales contenidos en una ley.

Citando a Flores Valeriano (1990) sobre la definición de esta fuente del Derecho Tributario podemos señalar que el:

Reglamento es un conjunto de normas de carácter legislativo expedidas por el Poder Ejecutivo, en ejercicio de la facultad que la Constitución de la República confiere, para proveer en el orden administrativo, al cumplimiento de las leyes ordinarias que dicta el Poder Legislativo (p.158).

En este mismo sentido opina Escorcia, al enunciar que "los Reglamentos son definidos como aquellos mandamientos generales y abstractos emanados del Poder Ejecutivo" (2002, p. 110). Es decir, el Reglamento es una norma o conjunto de normas jurídicas, que expide el Poder Ejecutivo, en uso de la facultad que le es atribuida por la Constitución (art. 150 inc. 10) o por una ley, cuyo objeto es facilitar la exacta observancia de las leyes expedidas por el Poder Legislativo.

En ésta misma línea, sostiene Ferreiro Lapatza (1990) que:

Los reglamentos deben ser siempre y solamente "el complemento indispensable" de la ley a la cual desarrolla, y esto entendido en un doble sentido. Por un lado el reglamento debe incluir todo lo indispensable para que se asegure de manera correcta la aplicación y plena efectividad de la ley y, por otro, sólo debe incluir lo indispensable para cumplirla (p. 236).

Así las cosas, es claro señalar que el acto normativo por excelencia de la Asamblea Nacional es la Ley; y que el acto normativo por excelencia del Poder Ejecutivo es el Reglamento; potestad atribuida a éste último de producir normas jurídicas en todos los ordenamientos, consecuencia lógica de su posición de poder y de su competencia y responsabilidad en el gobierno del Estado. 
Por otra parte, los Decretos son mandatos o decisiones de una autoridad superior sobre un asunto de su competencia. El Decreto es una decisión escrita del Poder Ejecutivo, por medio del cual se emite reglas de Derecho generales, abstractas e impersonales (Escorcia, 2002).

El art. 150 numeral $4^{\circ}$ de la Constitución del año de 1987 , establecía como atribución del Presidente de la República, la facultad de: "Dictar Decretos Ejecutivos con fuerza de ley, en materias de carácter fiscal y administrativo". Dicha atribución convertía al Poder Ejecutivo en Poder Legislativo, debido a que aquellas materias de carácter fiscal y administrativo que podía regular mediante Decretos con fuerza de ley, la Constitución las asimilaba a las propias leyes lo que conllevaba en consecuencia de ello a la modificación o derogación de leyes formales mediante tales Decretos y en las materias antes mencionadas.

De esta manera, el referido art. 150.4 de la Constitución de 1987, discrepaba con el art. 115 de la misma Constitución -mismo que no fue objeto de modificación o derogación alguna- que señala:

Art. 115 "Los impuestos deben ser creados por la que establezca su incidencia, tipo impositivo y las garantías a los contribuyentes. El Estado no obligará a pagar impuestos que previamente no estén establecidos en una ley".

Esta delegación legislativa del Poder Ejecutivo de dictar "Decretos Leyes" a partir de 1987 surgió de los legisladores para que en período de receso de la Asamblea Nacional, fuese éste Poder del Estado el facultado de crear éstos actos jurídicos de contenido legislativo.

Evidentemente, los Decretos Leyes, ya no son posibles en nuestro país, ya que las funciones legislativas en materia tributaria no son delegables. En líneas anteriores se ha señalado que la potestad tributaria normativa en nuestro país está reservada exclusivamente al Poder Legislativo, esto es, que los límites y contenido de esta producción de normas tributarias de rango reglamentario por parte del Poder Ejecutivo debe ser acorde con la norma suprema constitucional (Balladares Saballos, 2007). Aún más, los Reglamentos tienen un doble límite, ya que además de ostentar una subordinación a la Constitución, lo están en torno a las leyes; no solo a la que reglamenta, sino a todas las leyes, por ser el Reglamento una norma de inferior rango normativo. (Herrera Espinoza, 2006). 
De esto se desprende que, ningún otro poder del Estado que no sea el Poder Legislativo se encuentra habilitado para ejercer la potestad tributaria normativa; por cuanto el art. $114 \mathrm{Cn}$. establece claramente que ésta potestad de aprobar, modificar y suprimir tributos, es función exclusiva e indelegable de la Asamblea Nacional de la República de Nicaragua.

\section{La jurisprudencia}

Según expresa Ossorio (2006):

En términos más concretos y corrientes, se entiende por Jurisprudencia la interpretación que de la ley hacen los tribunales para aplicarla a los casos sometidos a su jurisdicción. Así, pues, la Jurisprudencia está formada por el conjunto de sentencias dictadas por los miembros del Poder Judicial sobre una materia determinada (p. 552).

Si se entiende por fuente de Derecho Tributario las formas de producción de normas de esta naturaleza, la Jurisprudencia no puede incluirse entre ellas; ya que como se ha expresado a lo largo de esta investigación, y coincido con Calvo Ortega "el principialismo tributario, es fundamentalmente constitucional” (1997, p.104). Además, por lógica natural, es comprensible ésta aseveración, si se piensa que la función judicial no tiene por objeto la producción del Derecho sino su aplicación a los casos controvertidos.

Considero que la Jurisprudencia de la Corte Suprema de Justicia, en todas las materias del Derecho, completa el ordenamiento jurídico, incluso, auxilia en la interpretación de la Constitución y las leyes, al precisar sus normas y determinar el alcance de sus principios.

En suma, cabe explicar que el principio de legalidad que tanto peso tiene en el orden tributario, impide considerar la existencia de esta fuente como norma; ya que no puede ser considerada para la regulación de los tributos, al carecer ésta de carácter de ley, puesto que no se puede integrar a través de la jurisprudencia elementos de cuantificación del tributo; pues como se ha dicho anteriormente, esto se encuentra reservado de forma exclusiva a la Asamblea Nacional a través de la aprobación de una ley. 


\section{Las disposiciones de carácter general}

De previo a desarrollar este acápite, es menester señalar acerca del nombre con el que se referirá a esta fuente de Derecho Tributario, pues de la lectura del Código Tributario, se desprende que no existe uniformidad en su denominación, aunque al parecer siempre se refieren al mismo sujeto. Como ejemplo de esto tenemos el artículo dos numeral seis del Código Tributario que le llama "disposiciones de carácter general"; por otro lado, en el artículo ciento cincuenta y dos numeral tres, se le llama "Disposiciones administrativas"; por último en el artículo doscientos veintitrés se le denomina "normativa general". Para efectos de comprensión en el presente trabajo, se le denominará, en estricto cumplimiento a la razón del porqué de su mención en estas líneas como disposiciones de carácter general.

De acuerdo con Herrera Espinoza (2006) éstas:

... son comunicaciones dirigidas a los contribuyentes, por parte de la Administración Tributaria, que tienen como finalidad la interpretación o aclaración del sentido en que debe entenderse una norma tributaria, ya sea ésta Ley o Reglamento. (p. 32).

De esto podemos deducir que se refieren a disposiciones puramente internas, dictadas en uso de la potestad de organización de los servicios o del principio jerárquico.

En este punto, es menester señalar que la doctrina mayoritaria hace distinción entre la actividad normativa de la Administración Tributaria, derivada de una potestad reglamentaria, y la actividad interpretativa surgida vía jerárquica, con ocasión de la aplicación de las normas. (Balladares Saballos, 2007).

En virtud de ello, no se evita que: a) existan discrepancias doctrinales; b) la existencia de discrepancias entre órganos situados al más alto nivel jurisdiccional (Corte Suprema de Justicia) y consultivo (Administración Tributaria); c) que en la práctica diaria sea muchas veces, difícil distinguir entre el producto derivado de una y otra actividad, debido a similitudes de contenido, coincidencia de titularidades y fungibilidad de las formas utilizadas en su emanación; d) la existencia de abusos de las formas jurídicas apropiadas para obtener los efectos deseados; e) 
que la presencia de una disposición de difícil catalogación (la consulta) complique aún más el panorama descrito (González García, 2000).

Ante tales hechos, podemos decir, según lo expuesto por Trzaskalik (2001), que:

La calificación de tales disposiciones como normas jurídicas carece de consecuencia, por cuanto deben organizar tan solo la vida interna de la administración. No constituyen, pues, una manifestación del poder legislativo, que compete al Parlamento, sino que están fundadas, mas bien, en el poder organizativo de la administración. (p. 686).

Así pues, podemos añadir que las disposiciones de carácter general, en cuanto a su forma de interpretación, no tienen carácter obligatorio para los particulares; por lo que su validez dependerá de que la disposición en cuestión se ajuste a la ley, pudiendo en el supuesto contrario, hacerse uso de los recursos jurisdiccionales legalmente establecidos (Flores Valeriano, 1990).

Por consiguiente, las disposiciones de carácter general son un instrumento auxiliar para el desempeño de los servicios públicos que integran la Administración Tributaria. Su contenido se agota en reproducción de leyes administrativas, interpretación de éstas, o bien en instrucciones sobre la realización de determinadas tareas.

\section{Potestad sancionadora en materia tributaria}

En la actualidad, la acción del Estado social de Derecho ha utilizado nuevas técnicas de control social, distinguiéndolas profundamente de las del Estado liberal clásico, empleando técnicas de incentivo o positivas junto a, o en sustitución de, las tradicionales técnicas de desincentivo o negativas, logrando superar la idea que consideraba al Derecho desde un punto de vista de su función protectora y a la que consideraba desde su función represiva. (Bobbio, 1990).

A pesar de que en la teoría general del Derecho contemporáneo la concepción represiva del Derecho es todavía existente; las exigencias del Estado asistencial han permitido que el Derecho no se limite a 
tutelar actos conforme a sus normas, sino que tienda a estimular actos innovadores y, de este modo, su función no es ya solamente protectora, sino que también promocional. (Bobbio, 1990).

En esta línea, conviene distinguir las normas positivas y normas negativas, así como las sanciones positivas de las sanciones negativas. En lenguaje común, una cosa es la distinción entre mandatos de prohibiciones y otra la distinción entre premios y castigos. (Bobbio, 1990).

Según Bobbio (1990):

En la literatura filosófica y sociológica el término "sanción", se usa en sentido amplio para incluir en él no sólo las consecuencias desagradables de la inobservancia de las normas, sino también las consecuencias agradables de la observancia, distinguiéndose en el genus sanción las dos especies de las sanciones positivas y de las sanciones negativas. Es un hecho sin embargo, que el término sanción en el lenguaje jurídico, si se usa sin más precisiones, denota exclusivamente a las sanciones negativas. (p. 375).

En definitiva, entonces, en el caso que nos ocupa expondré la figura del Estado como organismo que dicta leyes en función de protección de los actos lícitos, mediante la represión de los actos ilícitos.

\section{Referencias conceptuales}

La norma tributaria exige que se prevea la reacción del ordenamiento jurídico-tributario ante sus posibles violaciones, de igual manera que en otras parcelas de la órbita jurídica. A través de esto, se intenta restituir el orden jurídico transgredido y adoptar medidas represivas y ejemplificativas que propendan a que no se desarrolle una actuación lesiva para los intereses que protege la norma tributaria. (Cazorla Prieto, 2008).

Según expresa Pérez Royo, "el ejercicio del poder punitivo del Estado en relación con las violaciones de los deberes impuestos por las leyes fiscales se lleva a cabo mediante una doble vía: la penal propiamente dicha, y la administrativa" (2008, p.387). 
En este marco, Cazorla Prieto, (2008) nos aclara que:

La reacción de naturaleza administrativa se condensa en las acciones y omisiones constitutivas de infracciones tributarias y se lleva a efecto a través de las sanciones tributarias. Por el contrario, la reacción de naturaleza penal se condensa en los delitos contra la Hacienda Pública y se lleva a efecto a través de las penas.

En el Título IV "Deberes y Obligaciones de los Contribuyentes y Responsables Recaudadores" Capítulo II referido a "Ilícitos Tributarios" en su Sección I denominada "Infracciones Administrativas Tributarias" nuestro Código Tributario, en su artículo ciento catorce de manera limitada, nos brinda un concepto sobre el Ilícito Tributario y dice que: "Constituye ilícito tributario todo incumplimiento de normas tributarias sustanciales o formales". En esta misma línea, el legislador acoge la distinción antes señalada, al considerar en su artículo ciento quince, que: "Los ilícitos tributarios se clasifican en: 1. La Infracción Tributaria y 2. El Delito Tributario".

El Código Tributario en su artículo ciento dieciséis (116) establece que:

Concepto de infracción tributaria art. 116. Toda acción u omisión del cumplimiento de los deberes sustanciales del contribuyente que provoca un perjuicio pecuniario al fisco y que implica violación de leyes y reglamentos tributarios, constituye infracción administrativa tributaria sancionable en la medida y alcances establecidos en este Código.

La entrada en vigencia del nuevo Código Penal, ley seiscientos cuarenta y uno, en el año dos mil ocho, derogó expresamente el artículo ciento cuarenta del Código Tributario, el cual definía a los delitos tributarios de la siguiente forma:

Concepto art. 140. Es la amenaza o daño del patrimonio fiscal mediante el incumplimiento doloso de las obligaciones tributarias del contribuyente o responsable, con la clara intencionalidad dolosa del sujeto y cuya responsabilidad podrá ser determinada de conformidad a lo establecido en la legislación penal vigente. 
A la fecha, es menester entonces señalar que los tipos penales, así como las disposiciones generales de carácter conceptual referidas a los delitos tributarios, se encuentran exclusivamente normados por el recientemente aprobado Código Penal.

Ello no obstante, es meritorio diferenciar las infracciones tributarias y los delitos contra la Hacienda Pública, a la luz de lo determinado por la doctrina. En este sentido, la doctrina mayoritaria considera que son tres los criterios de distinción: a) por el órgano de su conocimiento (administración tributaria y jurisdicción penal); b) por el cauce para su sustanciación (procedimiento administrativo y proceso penal); y c) por la manera como reacciona el ordenamiento jurídico ante tales violaciones, que no es más que la naturaleza de las propias sanciones (sanciones administrativas y penas de privación de libertad y multas). (Herrera Espinoza, 2006).

\section{Naturaleza jurídica}

Siguiendo el carácter previsto por el ordenamiento jurídico para cada tipo de ilícito; es claro enunciar que las infracciones administrativas tienen un carácter punitivo o represor, lo que hace que estas instituciones se encuentren en el ámbito del Derecho sancionatorio. A como señala Pérez Royo "hoy constituye opinión unánime la de que las diferencias entre estas sanciones y las jurídico-penales propiamente dichas no son sustanciales, sino puramente formales" (2008, p. 387).

En adición a esto, Sainz de Bujanda (1993) citado por Cazorla Prieto (2008, p. 548), expresa que:

No existe distinción sustancial entre ambos tipos de infracciones y que, en rigor, la única separación entre las infracciones contenidas en el Código Penal y las contenidas en otras leyes es de tipo formal, atendiendo exclusivamente a las valoraciones político-sociales. Existen infracciones que se incorporan al Código Penal para destacar la especial gravedad que se les atribuye con arreglo a este tipo de valoración político-social. Otras quedan subsumidas en el cuadro de la legislación administrativa por reputarse inferior de gravedad para el cuerpo social o de inferior rango los bienes jurídicos lesionados. 
En este mismo sentido, se expresa Menéndez Moreno (2001), de lo que se colige, que es pura opción de política legislativa la que separa las infracciones administrativas de las penales; puesto que el bien jurídico protegido es el mismo lo que varía es la intensidad de la protección.

En este sentido, cuando se cometa una infracción se impondrán sanciones administrativas, comúnmente de índole pecuniaria; "ya que, por imperativo constitucional, la Administración está imposibilitada de imponer sanciones que, directa o indirectamente, impliquen privación de libertad" (Herrera Espinoza, 2006, p. 79). Al contrario, al cometer un delito, sí se prevé la imposición de penas de privación de libertad.

Lo antes referido lo consagra el artículo ciento veintitrés del Código Tributario, que dice:
Alcance art. 123 C. Trib: Las sanciones por la comisión de infracción tributaria deberán ser impuestas por la Administración Tributaria con sujeción a los procedimientos establecidos en este Código.

Siguiendo a Cazorla Prieto (2008) es menester señalar que el deber de contribuir enunciado en el art. $114 \mathrm{Cn}$. es, en términos genéricos, el bien jurídico protegido por los ilícitos tributarios, aunque quepa distinguir en concreto que la protección directa de los intereses recaudatorios será la causa jurídica de la protección administrativa, mientras que el patrimonio de la hacienda pública lo será del ámbito penal.

De acuerdo con los objetivos planteados para esta investigación, me dedicaré a desarrollar el ilícito tributario de índole administrativo.

\section{De las infracciones tributarias}

En líneas anteriores se ha expuesto que la infracción tributaria es una violación al ordenamiento jurídico tributario y en consecuencia un ilícito tributario.

Partiendo del concepto que brinda el Código Tributario en su artículo ciento dieciséis (116) procederemos a delimitar los distintos elementos que conforman la infracción tributaria. 


\subsection{Elementos de las infracciones tributarias}

De acuerdo con los elementos delineados por Cazorla Prieto (2008) constituyen componentes de la infracción tributaria los siguientes:

1. La acción: Ésta debe entenderse tanto en sentido positivo como negativo; esto implica según Calvo Ortega (1997) que el incumplimiento a la norma legal "puede ser realizado a través de una acción (una actividad del sujeto que realiza indebidamente un mandato de la norma) o de una omisión (no realización en toda su extensión y precisión de ese mismo precepto)" (p. 419).

Además, cabe seguir abundando en lo señalado por Calvo Ortega (1997) en el sentido que:

Siendo el tributo una obligación legal (pagar una suma de dinero) para cuya determinación y cuantificación se precisa la realización de determinadas obligaciones de hacer (deberes), parece claro que la mayor parte de las infracciones consistirán en una omisión (p. 419).

2. La tipicidad: Sobre este punto expresa Cazorla Prieto que "la tipicidad impone la necesidad de que la acción u omisión constitutiva de la infracción tributaria sea formulada con claridad y precisión en los elementos definitorios de su estructura" (2008, p. 551).

Distinto al concepto de infracción tributaria brindado por el artículo ciento ochenta y tres inciso primero de la Ley General Tributaria española que dice "Son infracciones tributarias las acciones u omisiones dolosos o culposas con cualquier grado de negligencia que estén tipificadas y sancionadas como tales en esta u otra ley", el concepto que brinda nuestro ordenamiento jurídico no contempla que las infracciones tributarias han de ser "tipificadas".

Sin embargo, en el artículo ciento diecisiete (117) de nuestro Código Tributario se enuncia la nómina de infracciones tributarias que ha trazado el legislador que, a su vez, constituyen el tipo legal objeto de castigo, y que dice así:

Art. 117. Constituyen infracciones tributarias:

1. El incumplimiento de los deberes y obligaciones de los contribuyentes y responsables, descritos en el presente Código; 


\section{La mora;}

3. La omisión de presentar declaración o presentada tardíamente

4. La contravención tributaria; y

5. El incumplimiento de los deberes y obligaciones de funcionarios de la Administración Tributaria.

3. La punibilidad: Esto refiere a que las infracciones tributarias han de ser sancionadas; ya que al ser punibles, es decir, susceptibles o merecedoras de penas violan el interés jurídicamente protegido por la norma tributaria.

4. La legalidad: Esto implica que los actos de acción u omisión han de transgredir preceptos normativos enunciados en la "ley y reglamento tributario". Posteriormente profundizaremos más en lo relativo a este elemento de infracción.

5. La imputabilidad: De acuerdo con Ossorio (2000) "un individuo considerado como capaz ante la ley es imputable siempre que pueda probarse que obró con plena comprensión del alcance de su acto, así como de las consecuencias" (p. 498). En este sentido, el acto u omisión, ha de ser imputable personalmente a su autor, y de esta manera el artículo ciento siete (107) del Código Tributario, dice:

La responsabilidad por la comisión de infracciones no trasciende de la persona del infractor, salvo las excepciones contenidas en este Código. Únicamente son responsables de las infracciones administrativas tributarias los autores de las mismas.

Son autores de las infracciones administrativas y de los delitos tributarios quienes realicen el hecho u omisión por sí solos, conjuntamente o por medio de otro del que sirven como instrumento.

Contrario al ordenamiento jurídico español, al parecer nuestro Código Tributario no detalló incluir como elementos de las acciones de infracción tributaria el dolo o la imprudencia.

A continuación, conviene hacer referencia que al igual que en los demás ordenamientos jurídicos sancionatorios, se exige que para hablar de infracción se contemple una serie de requisitos o principios que deben de ser observados, de los cuales haremos mención a continuación.

\subsection{Principios de la potestad sancionadora tributaria}

De manera explícita nuestra legislación tributaria no contempla los mandatos de optimización que regulen el ejercicio de la potestad sancionadora por parte de la Administración Tributaria. Por el contrario, 
el ordenamiento español, en su artículo ciento setenta y ocho de la Ley 58/2003, de 17 de Diciembre, General Tributaria dispone que: "La potestad sancionadora en materia tributaria se ejercerá de acuerdo a los principios reguladores de la misma en materia administrativa con las especialidades establecidas en esta Ley. En particular serán aplicables los principios de legalidad, tipicidad, responsabilidad, proporcionalidad y no concurrencia”.

Además, la doctrina mayoritaria, entre ellos Martín Queralt, Lozano Serrano, Casado Ollero \& Tejerizo López (2008), refiriéndose a la posición que viene manteniendo el Tribunal Constitucional español, dicen que:

Desde hace muchos años y de forma reiterada: en el ámbito del ordenamiento administrativo sancionador-incluido, claro el tributario-son aplicables, con matices y sin intentos apresurados de traslados mecánicos de un ordenamiento a otro, los principios, formales y materiales, propios del ordenamiento penal (SSTC 18/1981, 76/1990, 50/1995, 14/1999, 194/2000, 276/2000,etc,).

A criterio personal, podemos señalar que la doctrina asume la aplicación de los principios generales del Derecho Penal en el ámbito aplicativo de las infracciones tributarias, por lo que procederemos al análisis de éstos.

\subsubsection{Principio de legalidad}

Se ha expuesto este Principio en hojas anteriores, que solo mediante ley el Estado puede imponer sacrificios patrimoniales a los ciudadanos. De igual manera, en el ejercicio de la potestad sancionadora, "ha de ser una ley la que tipifique y sancione las infracciones tributarias" (Cazorla Prieto, 2008, p. 552).

En este supuesto, cabe aplicar el aforismo latino "nullum crimen, nulla poena sine praevia lege”. Ningún crimen, ninguna pena sin ley previa; lo cual según Ossorio "constituye una garantía individual, en cuya virtud no se puede interpretar que un acto cualquiera es delictivo o incurso en sanción penal, si no ha sido considerado expresamente como tal en una norma anterior" (2000, pp. 653). Esto se encuentra confirmado en el numeral cinco del artículo tres del Código Tributario que dice: "Solo mediante ley se podrá: ... 5) Definir las infracciones, los delitos y las respectivas sanciones”. 
Esta disposición deja constancia de la exigencia de una ley para tratar lo pertinente a las infracciones tributarias, a los delitos contra la Hacienda Pública y sus respectivas penas.

\subsubsection{Principio de tipicidad}

Siguiendo lo prescrito por Pérez Royo (2008):

La tipicidad es una exigencia que debe mantenerse como algo distinto de la legalidad o reserva de ley. Mientras esta última, se refiere a la forma, a los modos de creación del derecho, la tipicidad alude al contenido: la ley debe definir con contornos precisos los tipos de las infracciones, permitiendo a sus destinatarios conocer claramente el mandato o prohibición y la sanción aplicable a la violación de uno u otro. Y restringir dentro de los limites reducidos la discrecionalidad (empleamos este término en sentido no técnico) de la autoridad en la graduación de las sanciones (p. 389).

Dicho esto, considero de suma importancia la aplicación de este principio en toda norma que regule el ejercicio sancionador en materia tributaria, ya que conceder la atribución de imponer infracciones de manera discrecional a la Administración, podría implicar en algunos casos arbitrariedad.

Así pues, resaltemos la parte infine del artículo cuatro del Código Tributario:

La analogía es procedimiento admisible para llenar los vacíos legales, pero en virtud de ella no pueden crearse tributos, ni exenciones, exoneraciones $\mathrm{u}$ otros beneficios, como tampoco puede tipificarse infracciones o delitos, ni establecer sanciones. No se podrá aplicar la analogía cuando por esta vía se contraponga, altere o modifique cualquiera de las disposiciones legales vigentes en materia tributaria.

En este mismo sentido, Calvo Ortega señala que "la analogía lesionaría claramente el principio de reserva de ley, ya que el supuesto de hecho al que se aplica la norma estaría determinado no por la ley, sino por su similitud con otro establecido por otra norma legal” (1997, p. 420). 
Por último, interesa hacer referencia a que la tipificación también es obligada y acertada. Su establecimiento debe ser además general (para todos los hechos que reúnan sus requisitos) y abstracto (no establecido en contemplación de un sujeto determinado). (Calvo Ortega, 1997).

\subsubsection{Principio de culpabilidad}

Entiendo que el elemento de la culpabilidad en las acciones u omisiones debe ser "dolosas o culposas". De acuerdo con García Berro (2004) citado por Cazorla Prieto (2008, p. 552):

La concurrencia de culpa, siquiera en su grado más leve, para sancionar cualquier ilícito administrativo y, en particular, las infracciones tributarias, constituye una exigencia no cuestionable en la actualidad, como bien se encargó de poner de manifiesto hace tiempo nuestro Tribunal Constitucional.

En este sentido, parece ser que nuestro ordenamiento jurídico de forma explícita, no enuncia el elemento de la intencionalidad "culpa y dolo" como constitutivo de una infracción tributaria, pues únicamente percató hacer énfasis en la intención dolosa como elemento constitutivo en los Delitos Tributarios; mas no lo hizo en las infracciones tributarias.

Es menester señalar que el código tributario en su artículo ciento ocho, estipula causales de exclusión de responsabilidad administrativa. Al respecto, Calvo Ortega (1997) enuncia que:

La causa de exclusión de culpabilidad más importante es la actuación del sujeto pasivo con una diligencia normal. Ello supone, obviamente, y como veremos, posteriormente, la actuación de buena fe, e igualmente y también de manera indiscutible, la ausencia de dolo y negligencia grave y media.

Por ello, a criterio personal, considero que la "culpa y el dolo" son elementos constitutivos de las infracciones tributarias, según el tipo.

\subsubsection{Principio de no concurrencia o de ne bis in idem}

Estimo que éste principio, constituye que no se puede sancionar dos veces un mismo hecho; esto implica que a cada infracción corresponde, 
pues, una sanción, salvo determinadas eximentes (Calvo Ortega, 1997). En ésta misma línea expresa que:

Hay que entender este principio básico del Derecho sancionatorio aplicable a las sanciones tributarias. Se trata, también, de un principio exigido por la justicia y por la lógica jurídica: no dos sanciones por la misma infracción jurídica ni al mismo sujeto ni a otros sucesivamente cualesquiera que sean sus destinatarios (p. 419).

Así parece deducirse de la letra del artículo ciento dieciocho del código tributario al expresar que: "Cuando alguna persona sea responsable de diversas infracciones, por cada una de ellas se aplicará la sanción respectiva" máxime cuando nuestro ordenamiento jurídico atina al invocar este principio, al contemplar una lista de sanciones numerus clausus para cada una de las infracciones.

No obstante, considero que nuestra legislación tributaria contiene una debilidad jurídica, en lo referido a la valoración de los hechos. Al parecer, éste supuesto lo deja a criterio de la Administración Tributaria en el caso que iniciado el procedimiento administrativo e impuesta la sanción correspondiente los hechos sancionados ameriten ser catalogados como delitos contra la Hacienda Pública.

\section{Sujetos responsables de las infracciones y sanciones tributarias}

Tomando en cuenta, que el tributo es un ingreso público, una prestación pecuniaria exigida por un ente público, de ello se deduce la existencia de un sujeto activo y un sujeto pasivo. Sobre esta línea, siendo que las violaciones a los deberes de tributos, son realizadas por las personas que realicen las acciones $\mathrm{u}$ omisiones al cumplimiento de los deberes sustanciales de contribuyentes; podemos manifestar que sujeto infractor será el sujeto pasivo, obligado en virtud de la ley, al cumplimiento de la obligación tributaria (art. 16 CTrib). En adición a esto, de la lectura del mismo cuerpo de leyes, podemos añadir que se consideran sujetos infractores: las personas físicas o jurídicas, sociedades de hecho, que realicen las acciones $\mathrm{u}$ omisiones señaladas como infracciones en el ordenamiento jurídico.

Sin perjuicio de lo anterior, conviene agregar que otros sujetos distintos del contribuyente pueden verse obligados por la ley al cumplimiento de 
todas o algunas de las prestaciones tributarias, como es el caso de los "Responsables" y así tenemos a los responsables por deuda tributaria ajena, responsable retenedor y responsable recaudador (art. 19-20 CTrib).

En esta línea, el artículo ciento siete (107) de nuestro Código Tributario, previamente enunciado, expresa que en materia tributaria, se admite el principio de la responsabilidad personal.

Según Pérez Royo "las consecuencias de la infracción no pueden ser exigidas más que a las personas que con su comportamiento han causado la lesión constitutiva de la misma infracción" (2008, p. 393). En este sentido, atendiendo a la disposición legal antes referida podemos deducir que la responsabilidad por infracciones tributarias es personal y por consiguiente no es transmisible.

En adición a esto, conviene mencionar la parte infine del art. 107 CTrib., que dispone la autoría de las infracciones tributarias cuando existe pluralidad de sujetos.

En lo que hace a la responsabilidad de las personas jurídicas, es meritorio recalcar lo que expone Pérez Royo (2008):

La regla tradicional del Derecho Penal es la de que las personas morales no pueden ser responsables penalmente (societas delinquere non potest). En el ámbito de las infracciones administrativas, la cuestión se plantea de manera muy diversa, ya que, al no tener cabida las penas de privación de libertad, las personas jurídicas pueden recibir directamente la sanción derivada de la infracción. Las personas jurídicas pueden, pues, tener la condición de sujeto infractor, aunque, como es natural, el requisito del elemento subjetivo (el dolo o culpa) deberá ser apreciado en el comportamiento de las personas físicas que actúan como órganos o representantes. Estas personas podrán, además, ser consideradas como responsables de la sanción, junto a la persona jurídica a la que se atribuye como sujeto principal de la infracción (p. 394).

En esta misma línea Martín Queralt, Lozano Serrano, Casado Ollero \& Tejerizo López dicen que: "La imputabilidad a personas jurídicas de la comisión de infracciones tributarias encuentra una explicación en 
el hecho de que la sanción impuesta, al tener contenido patrimonial, puede perfectamente ser asumida y cumplida por las personas jurídicas" (2008, p. 560). En nuestro sistema, al parecer el artículo ciento doce del Código Tributario, acoge esta idea, al imputar de manera vaga la idea de que las personas jurídicas pueden ostentar responsabilidad administrativa y por consiguiente considera que son objeto de sanciones las personas jurídicas, entidades o colectividades y sociedades de hecho por la comisión de infracciones administrativas tributarias.

Además, nótese que en el artículo posterior (art. 113 CTrib) se continúa acogiendo el principio de responsabilidad personal para aquellos funcionarios de una entidad que incurran en infracciones tributarias.

Por último (Martín Queralt, Lozano Serrano, Casado Ollero \& Tejerizo López, 2008; Cazorla Prieto, 2008; Pérez Royo, 2008) concluyeron que las sanciones tributarias no son transmisibles a los herederos y legatarios de las personas físicas. En cambio en las sanciones impuestas a personas jurídicas, es distinto, pues en este caso sí que se transmiten a los sucesores. A esto último conviene recalcar que Simón Acosta (2004) citado por Cazorla Prieto sostiene (2008) que: "No es razonable que el sucesor de la persona jurídica se enriquezca mientras no estén satisfechas las responsabilidades pecuniarias en que haya incurrido la persona jurídica por comisión de infracciones".

\section{Límites de la potestad sancionadora tributaria}

De manera desacertada nuestro legislador otorgó facultades normativas a la Administración Tributaria para normar por ministerio de ley sobre procedimientos de casos no regulados por una ley general o especial. Éste es el caso del art. 223 del Código Tributario:

Sin perjuicio de las facultades establecidas en el presente Código y demás leyes tributarias, el titular de la Administración Tributaria mediante normativa general determinará los procedimientos a aplicar, entre otros, para los siguientes casos:

1. Intervención administrativa;

2. Clausura de negocios;

3. Autorización de sistemas informáticos parallevar contabilidad, facturas, ticket de máquinas registradoras;

4. Procedimientos especiales para: 

a. Notas de crédito
b. Emisión de boletines informativos;
c. Dictamen final
d. Evaluación de consultas;
e. Registro de contribuyentes,
f. Reembolsos; $y$

5. Cualquier otra disposición que se considere necesaria para el cumplimiento de lo establecido en el presente Código, siempre que tal situación no implique alteración alguna a las disposiciones contenidas en la presente ley.

A esto se le denomina facultad legislativa delegada, a lo que García de Enterría (1986) dice:

El fenómeno de la llamada genéricamente legislación delegada, es uno de los más importantes en la práctica actual de todos los países. Crecientemente, en efecto, el legislador hace participar de alguna manera a la Administración en la ordenación jurídica de la sociedad actual y de sus problemas. Cada vez se va generalizando más esta forma legislativa que supone una participación entre el legislativo, que adopta ordinariamente la iniciativa y la Administración, que la continúa y la lleva a término y conclusión. (p. 251).

Sobre este punto, los procedimientos a normar en la disposición legal antes citada, no fueron regulados en el Código Tributario, y no se establecieron sus alcances, ni garantías a los contribuyentes. Al respecto, Herrera Espinoza (2006, p. 93) dice: "parece que el art. 223 del Código Tributario no respeta el principio de legalidad, en cuanto otorga facultades de legislador al Titular de la Administración Tributaria, con el mandamiento de preparar normativas de procedimientos". En adición a esto, continua exponiendo el autor, "que mas que transgredir el principio de legalidad ... con la opción normativa consagrada en el artículo 223 transgrede uno de los principios rectores del sistema tributario nicaragüense: el de 'seguridad jurídica'". 
En este mismo sentido, López Rocha (s. f.) citado por Herrera Espinoza (2006) dice:

... La Asamblea Nacional no debe delegar la facultad de normar al Titular de la Administración Tributaria, sobre casos que no fueron regulados previamente a través de ley, en caso contrario se estarían otorgando responsabilidades legislativas a la Administración Tributaria. La Asamblea Nacional debió haber establecido que dichos procedimientos van a ser regulados por leyes especiales de procedimientos administrativos tributarios. La Asamblea Nacional tiene la obligación de asegurar garantías a los contribuyentes por mandato constitucional. La administración tributaria, tiene la obligación de cumplir y hacer cumplir las leyes, pero, bajo ninguna circunstancia puede tener funciones legislativas, y menos por mandato de ley; porque se ubicaría en la situación de ser Juez y parte. (p. 92).

Nos encontramos pues, ante una habilitación conferida a la Administración Tributaria para que utilice su poder reglamentario propio en complementar una normativa concreta, y determinada por su contenido.

Nótese que el artículo citado hace referencia a dos tipos de sanciones aplicables por la comisión de una infracción tributaria. Dicho lo anterior, toda acción hecha por parte de la Administración Tributaria para regular el ejercicio sancionatorio en esta materia debe ser acorde con el contenido de la ley con el fin de garantizar la eficacia del Derecho. En este sentido, conviene señalar la preeminencia de la ley, lo cual implica que las disposiciones contenidas en una ley de carácter formal, no pueden ser modificadas por una Normativa Administrativa.

Esta idea se ha repetido a lo largo de ésta investigación, puesto que no se puede definir una infracción o imponer una sanción por medio de una disposición de carácter general, ya que ello, acarrearía la ilegalidad e inconstitucionalidad de la misma.

En esta línea, ésta situación iría en contra del Principio de Reserva de Ley, en que conforme a la Constitución, existen materias que solo pueden ser reguladas por una ley; y siendo el caso de la creación, modificación, 
derogación y aplicación del sistema de tributos debe estar contenida en una ley; a claras luces se denota la ilegalidad de una disposición de carácter general que crease una infracción y en consecuencia su sanción. Inclusive, el tantas veces mencionado art. 115 de la Constitución de Nicaragua y el art. 3 CTrib, refiriéndose al principio de legalidad, establecen la creación de tributos mediante ley y en consecuencia su ejercicio, regulación y por consiguiente la imposición de sanciones ante las violaciones del deber de pago de impuestos, han de ser creados mediante ley. Es por ello, que deduzco la existencia de una antinomia, que otorga facultad normativa a la Administración Tributaria consagrada en el art. 223 CTrib, con la definida en el art. 3 del mismo cuerpo de leyes; pues el ejercicio de la regulación del pago de tributos, ha de ser creada exclusivamente mediante ley.

\section{Conclusiones}

1. La justicia tributaria es el resultado de la aplicación concreta del contenido esencial de cada uno de los principios que lo integran, presentes cada uno de ellos en el dictado constitucional. Asimismo, que éstos principios de justicia tributaria constituyen los pilares sobre los que se cimienta el conjunto de derechos y garantías de los contribuyentes. Como podemos ver, tratándose del ejercicio conferido a la Administración Tributaria para aplicar el sistema de tributos, éste debe apegarse para su correcta aplicación, a los principios de justicia tributaria que se encuentran dispersos y de manera subrepticia en preceptos de índole constitucional y en nuestro Código Tributario.

2. Una de las violaciones a los deberes de impuestos se lleva a efecto a través de las infracciones tributarias; consideradas como el incumplimiento por parte de los contribuyentes de los deberes sustanciales que provocan una lesión al fisco. Que dicha infracción tributaria, debe incluir claramente las valoraciones de los hechos considerados para incurrir en un ilícito, la forma en que se actuó y la norma transgredida y su sanción.

3. De igual manera que los principios de justicia tributaria, la potestad sancionadora de la Administración Tributaria contemplan sus propios mandatos de optimización, que persiguen la imposición justa de sanciones por las violaciones de los deberes impuestos por las leyes tributarias. Así pues, estos principios de la potestad sancionadora 
tributaria, son introducidos en la norma tributaria en virtud de traslado de los principios contemplados en el ordenamiento penal, $\mathrm{y}$ cabe recalcar que no se encuentran contemplados de forma visible en la norma tributaria, por lo que es necesaria la interpretación para la apreciación de éstos.

4. De manera general, se puede considerar a la fuente, como el manantial de donde brota el Derecho. En este sentido, la idea de fuente del Derecho es como aquellos hechos o sucesos, caracterizados por ciertas notas peculiares, con capacidad y eficacia suficiente para normar una serie de comportamientos intersubjetivos cuya observancia se considera necesaria para la conservación de los fines propios de la sociedad. No obstante, en el orden de nuestra tradición cultural y en el de la legislación positiva nicaragüense, la fuente esencial del Derecho es la ley, interpretada en su sentido más amplio de ley constitucional, y ordinaria. Las fuentes indirectas, tales como la jurisprudencia, y disposiciones de carácter general, resultan cuestionables ser aceptadas como fuentes del Derecho Tributario, pues éstas constituyen excepciones al principio de legalidad.

5. Se ha reconocido un problema en la práctica de la potestad legislativa tributaria, desde el punto de vista de la legitimidad de las normas indebidamente expedidas por la Administración Tributaria. Conviene señalar que la potestad para crear, modificar, suprimir y aplicar el sistema de tributos, deviene de la soberanía delegada del pueblo, y si no es en virtud de ella que se producen normas tributarias de carácter general, se cae en una infracción grave del trámite. Así, las normas técnicas de rango administrativo emitidas por la autoridad tributaria que implique el ejercicio de la aplicación de los tributos, en lo que hace a la imposición de infracciones y sanciones, acarrean consigo la causa de la ilegalidad.

\section{Recomendaciones}

1. Incluir de manera clara y detallada los principios que intentan resaltar la obra del legislador, evitando recaer en la interpretación para la localización de los mismos, a fin de que sean de fácil observancia tanto para el ente público como para los contribuyentes; ofreciendo que ante toda controversia de normas o posibles vacíos jurídicos, éstos, serian decididos o subsanados por los mismos principios que el legislador usó para la creación de la norma. 
2. Propongo se realice una mejor elaboración del ilícito tributario de carácter administrativo, en el sentido que en el mismo, se detalle de forma precisa los hechos en que se incurren en contravención a un deber, impuesto por la norma fiscal; tipificando la infracción y caracterizando el elemento intencional hecho por el sujeto infractor.

3. Incorporar en el Título conferido a las Infracciones y Sanciones de nuestro Código Tributario, los Principios en que se inspira la Administración Tributaria, para llevar a efecto el ejercicio de su poder punitivo, con el fin de brindar seguridad jurídica en la forma de imposición de sanciones y evitar importar principios inspiradores del ordenamiento jurídico penal.

4. Atendiendo al concepto usual de fuentes del Derecho como inspiradoras para la creación de una norma, en estricto respeto al principio de legalidad que tanta importancia tiene en el Derecho Tributario, se debería delimitar en la norma las fuentes formales que constituyen verdaderamente los procesos de creación de las normas jurídicas. En consecuencia, dejar de considerar a la jurisprudencia y las disposiciones de carácter general, como fuentes en sentido estricto; sino que detallar las mismas como sujetos de interpretación y orientación de las disposiciones normativas.

5. Se requiere que se diseñe una mejor aplicación en el sistema de aplicación de los tributos; empezando por incorporar el proceso ordenadamente bajo un capítulo dedicado únicamente a su desarrollo, inspirados bajo el principio de legalidad y seguridad jurídica. En esta misma línea, creo conveniente incorporar en una ley general o específica que regule lo concerniente al procedimiento a aplicar en la imposición de un tipo de sanción, evitando de esta manera una emigración de normas que pudieran estar contenidas en una ley formal a que pasen a ser objeto de regulación a través de una normativa administrativa, lo que acarrea incumplimiento al principio de legalidad y seguridad jurídica a favor de los contribuyentes.

\section{Lista de referencias}

\section{Textos}

Amatucci, A. (2001). Tratado de Derecho Tributario. Tomo 1, Bogotá: Temis.

Amatucci, A. (2001). El Derecho Tributario y sus fuentes. (2 ${ }^{a}$ ed.), Tomo 2. Bogotá: Temis. 
Báez Cortés J., y Báez Cortés T. (2007). Todo sobre impuestos en Nicaragua. ( $7^{\mathrm{a}}$ ed.). Nicaragua: Iniet.

Balladares Saballos, R., Bermúdez, R., González Mora, M., Silva Gutiérrez, M., Flores Miranda, E., González Gutiérrez, G., et al (2009). Análisis Jurídico del Sistema Tributario: Propuestas para su reforma en Nicaragua. Nicaragua: Impresiones Helios.

Bermúdez Pérez, A. (2009). Análisis al Régimen de Compensación y Devolución de Saldo en el Impuesto al Valor Agregado en el Sistema Tributario Nicaraguense. Tesis de Especialista en Derecho Económico no publicada, Universidad Centroamericana. Nicaragua.

Bobbio, Norberto (1990). Contribución a la Teoría del Derecho. España: Debate.

Calvo Ortega, R. (1997). Curso de Derecho Financiero I. Derecho Tributario Parte General. (3 ${ }^{a}$ ed.). España: Civitas.

Cazorla, Prieto, L. (2008). Derecho Financiero y Tributario: Parte General. (9 ${ }^{\mathrm{a}}$ ed.). España: Aranzadi.

Escorcia, J. (2002). Derecho Administrativo (Primera Parte) Concordado con la Legislación y Jurisprudencia Nacional. Nicaragua: Universitaria.

Ferreiro Lapatza, J. (1990). Curso de Derecho Financiero Español. (12 ${ }^{\mathrm{a}}$ ed.). Madrid: Marcial Pons.

Flores Valeriano, E. (1990). Derecho Administrativo. (3ra ed.). Honduras: Universitaria.

García de Enterría E., \& Fernández T. (1986). Curso de Derecho Administrativo I. (4 ${ }^{a}$ ed.). Madrid: Civitas.

González García, E., \& Lejeune E. (2000). Derecho Tributario I. (2 ${ }^{\mathrm{a}}$ ed.). Salamanca: Plaza Universitaria. 
Herrera Espinoza, J. (2006). Código Tributario de la República de Nicaragua y sus reformas. Incluye estudio introductorio $y$ Disposiciones Complementarias. Nicaragua: Impresiones Helios.

Jaentschke Acevedo, K. (2009). Análisis Jurídico del Impuesto al Valor Agregado en Nicaragua. Tesis de Especialista en Derecho Económico no publicada, Universidad Centroamericana. Nicaragua.

Malespín, F., Balladares Saballos, R., \& Ruíz, M. (2007). Algunas obligaciones básicas de la empresa: Derecho Laboral y de la Seguridad Social Empresarial; Derecho Tributario de la Empresa. Nicaragua: Xerox.

Martín Queralt, J. La potestad tributaria, en Amatucci, A. (2001). Tratado de Derecho Tributario. Tomo Primero, Tomo Segundo. El Derecho Tributario y sus Fuentes (pp. 141-156). Bogotá: Temis.

Martín Queralt, J.; Lozano Serrano, C.; Casado Ollero, G. \& Tejerizo López, J. M. (2008). Curso de Derecho Financiero y Tributario. (19 ${ }^{\mathrm{a}}$ ed.). España: Tecnos.

Menéndez Moreno, A. (2001). Derecho Financiero y Tributario. Lecciones de Cátedra. Valladolid: Lex Nova,

Ossorio, M. (2000). Diccionario de Ciencias Jurídicas Políticas y Sociales. (27 ${ }^{\mathrm{a}}$ ed.). Argentina: Heliasta.

Pérez Royo, F. (2008). Derecho Financiero y Tributario: Parte General. (18va ed.). España: Civitas.

\section{Legislación}

Constitución Política de Nicaragua, con sus reformas. 7ma. ed., Editorial Jurídica. Managua, Nicaragua, 2001.

Ley $\mathrm{N}^{\mathrm{o}}$ 598: Ley de Reformas al Código Tributario de la República de Nicaragua. Publicado en La Gaceta, Diario Oficial No 177 del 11 de Septiembre del año 2006. 
Ley No 562: Código Tributario de la República de Nicaragua. Publicado en La Gaceta, Diario Oficial No. 227 del 23 de Noviembre del año 2005.

Ley ${ }^{\circ}$ 58/2003, de 17 de Diciembre, Ley General Tributaria de España, publicado el 18 de Diciembre del año 2003 BOE No 302.

\section{Abreviaturas}

Cn.: $\quad$ Constitución Política

CTrib.: Código Tributario

LGTE: Ley General Tributaria Española 